\title{
Tempio Pausania: social conflict resolution in a community setting
}

\author{
Gian Luigi Lepri, Ernesto Lodi and Patrizia Patrizi
}

\section{Origins of the project}

In Tempio Pausania, a community of about 14,000 inhabitants in the north of the island of Sardinia, it all started with a conflict within the community when a new prison was built for inmates with life sentences for mafia crimes. The citizens of Tempio immediately feared the prisoners and of possible mafia infiltration in their local community, whereas the prisoners were worried about the great distance from their families. So, in agreement with the direction of the prison and the municipality, we started our pilot project: Study and analysis of restorative practices for creating a model of restorative community. The aim of the action research is to experience restorative practices which can involve the whole community: schools, families, police, courts, municipalities, associations, based on the model of the English restorative cities of Hull and Leeds.

Seminars and workshops involving the community and professionals such as journalists and lawyers were organised as they were thought to be good practices to raise awareness and to disseminate the principles of restorative justice and its practices. Since restorative justice has the immediate potential to combine the needs of rehabilitation and social security through community involvement and conflict management, we tried to build in Tempio Pausania an opportunity to establish a cultural change: trying to involve the community to create a restorative city; involving the schools, social services, NGO, police, church and commercial activities in adopting a model of restorative justice to give back to community the ability to manage and resolve conflicts and to live the everyday life in a more peaceful way (Wright, 2002, 2010). We tried to develop a sense of community, an important part of our restorative practices that involves a sense of emotional connection and security through significant ties with people and place (McMillan \& Chavis, 1986).

* Gian Luigi Lepri is a psychologist and psychotherapist coordinator of the Restorative Justice Practices Team, University of Sassari, Department of Humanities and Social Sciences - Dumas, Italy. Ernesto Lodi is researcher in Social Psychology at the University of Sassari, Department of Humanities and Social Sciences - Dumas, Italy. Patrizia Patrizi is full professor of Social Psychology and Psychology and Law at the University of Sassari, Department of Humanities and Social Sciences - Dumas, Italy, member of the board of the European Forum for Restorative Justice.

Contact author: gianluigi.lepri@me.com.

Tempio Pausania Restorative City: http://giustiziariparativa.comune.tempiopausania.ot.it/. 


\section{Theoretical and conceptual basis}

In our framework, we preferred an orientation to the generation/regeneration of social harmony between social partners through a search for consensus, sharing and social peace (Patrizi \& Lepri, 2011).

Several studies have shown that community-based programmes are more effective in significantly reducing re-offending and societal conflicts, which encourages responsibility and participation by supporting people in the management of conflicts and problems (Aos, Miller \& Drake, 2004; Cellini, 2009; McIvor, 1991; Petersilia \& Turner, 1993). In recent decades, the scientific community has acknowledged how the contribution of positive psychology redirected research attention to the growth and development of persons in their environment, aiming to promote skills and attitudes that match the complex reality in which they live (Catalano, Berglund, Ryan, Lonczak \& Hawkin, 2004; Nota, Ginevra \& Santilli, 2015). Central constructs in this perspective are: hope - the ability to set goals and identify the strategies needed to achieve them (Snyder, 2000); optimism - the ability to learn from experience and build positive future scenarios (Seligman, 2005); resilience - the ability to engage and persist even in the presence of failures and particularly negative events (Masten \& Powell, 2003); courage - continuing to face challenges for equity and social well-being (Snyder, Lopez \& Pedrotti, 2011), including challenging current norms and barriers in pursuit of the greater well-being of the community (Spreitzer \& Sonenshein, 2003); perceived self-efficacy - people's beliefs about their capabilities to exercise control over events that affect their lives; collective efficacy - a positive valuation shared by the members of groups/systems, equipped above individual characteristics (Bandura, 1997). We adopt a positive view of persons and context because we think that restorative practices are the best way to activate positive resources in people and their environments (family, friends, work, school, services, community, etc.).

In this framework, we are experimenting with a model of community that promotes lifestyles and conflict management marked by responsibility, peace and well-being: the Co.Re. (Community of Restorative Relationships) model. This model considers the results of previous researches in criminal justice and numerous researches that are still underway, both in the criminal sphere and in other contexts such as schools and neighbourhoods. It is in line with the latest scientific guidelines that support the need to develop intervention systems capable of reducing conflicts within the social dynamics and generating positive dynamics of inclusion and promotion (Figure 1).

The centreline of Figure 1 illustrates the main change in perspective that inspires the model: the shift from inclusion to well-being. This concerns the shift from a re-active to a pro-active mode. Inclusion is necessary but it is a goal-directed action after the negative effects of marginalisation, social exclusion, imprisonment, etc. Well-being is the vision, and its main goal is the benefit of everybody.

Ecological level. Reciprocity, obligations and responsibility are main concepts. They define this level that we have called ecological, referring to the ecology of 
Figure 1 Co.Re. (Community of Restorative Relationships) model

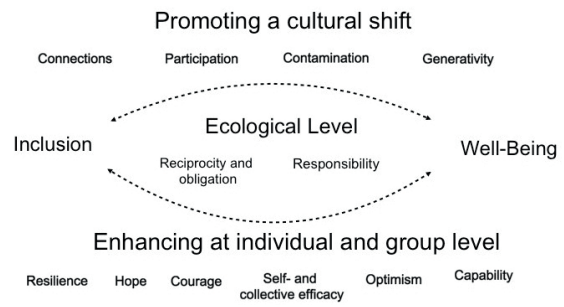

responsibility as theorised by Gaetano De Leo (1940-2006), ecological responsibility is a concept that is immediately and structurally interactive. It is not content inside our mind or a quality of consciousness and will; it is co-created in the relationship between subject, action, institutions and society, and at the same time, it is a pattern that organises the relationships between individuals, actions, rules and community. It is not an entity or a substance but a relational process; a quality emerging in the systems of reciprocity. De Leo (1996) examines the responsibility as a function culturally and socially built to connect: (1) psychological aspects: the self and the social performance of the individual; (2) interpersonal aspects and regulations to produce consistency and continuity of the social expectations and (3) institutional and social aspects to guide individual performance and collective expectations, maintaining adequate levels of order and predictability.

Cultural Level. Here, we try to promote a shift trough connection (people, institutions, groups), participation (proactive view), (positive) contamination (to exchange competence and fight prejudice), generativity (every action can build new sense and new actions).

Individual and Group level. Here, we use the positive psychology variables to improve well-being and social cohesion through interventions on resilience, hope, courage, optimism, capability and self and collective efficacy.

\section{Operationalisation}

The operationalisation of the project's actions were addressed with these specific aims:

- Building a restorative community model to share within the Sardinian context with social and institutional stakeholders.

- Identify, disseminate and promote good practices at a local level in relation to restorative justice programmes and mediation.

- Explore the strengths and critical elements in the implementation of a restorative model community.

Build networks between the agencies involved, in order to share experiences and practices aimed at the implementation of the model. 


\subsection{Intervention tools: restorative conferences}

The main instrument to build a sense of community and to reduce conflicts in Tempio Pausania consists of restorative conferences: a series of meetings in which different parts of the system come together to identify resources and channels for building a peaceful manner of problem and conflict resolution. The aim is to encourage everyone who is present, in different roles and memberships, to reflect on the meaning and potential of a relational key set community. Restorative conferences give the prisoners and community an opportunity to think about the links between territory and imprisonment. During the conference, open to the whole community, we have various kinds of participants (judges, volunteers, students, social practitioners, teachers, educators, third sector, administrators, law enforcement, etc.) and we registered about 900 people at eleven restorative conferences. On 19 November 2014, during the International Week of Restorative Justice, a restorative lunch was organised with the participation of a prisoner's delegation (having, for the first time in many years, the opportunity of a meal experience outside the penitentiary), local authorities, magistrates, lawyers, the mayors of Tempio Pausania and Sassari along with various councillors, etc. Each table was marked with the words emerged at the first restorative conference (the values of the conference, among others: responsibility, respect, trust and reciprocity).

\subsection{Other restorative actions}

Every year the restorative justice week is the opportunity to introduce new community restorative actions to strengthen social ties and to reach more citizens and stakeholders, such as: the restorative lunch, the restorative aperitivo, student flash-mob in the City main square, scientific workshops and seminars, and theatre performances with restorative contents.

\subsection{Research instruments: focus group, interviews and questionnaires}

To evaluate the results and changes in our community, we investigated social representation on concepts like justice and conflict resolution. The outcomes were used to evaluate changes after the conclusion of the project. The focus groups have also been used to design (until 31 December 2016) the restorative practices' community board. The interviews have been focused on effects of the participation to the project in terms of: Changes (mafia culture, relationships with others), Relationship with Victims, Future expectations about restorative justice programmes in Tempio.

\section{Ongoing processes}

The deeper meaning of the Tempio Pausania project is to: build together the possibility of managing conflicts peacefully, a sense of providing answers to damages that can be caused by a crime or by another type of action, in order to respect the rights of all involved parts.

As a result of this action research project, we can highlight three different levels of outcomes: perception, integration and innovation: 
1 At the level of perception, focus groups and questionnaires revealed the connection between variables of the research and the concept of justice: for example, according to the data analysis of the questionnaires, interventions on social support and resilience would probably have allowed to increase also the experiences of hope.

2 At the level of integration, the main result is demonstrated by a city council that took place in prison and strongly desired by the mayor and the municipal administration. It is a first stone placed by the 'formal community' in prison highlighting that where at first there was a division, we now have built a sense of sharing by overcoming stereotypical visions of buildings and persons (especially for the prison and prisoners) and by facing previous integration problems with a new point of view. Another point of integration is a strong relationship built between school, university and prison.

3 At the level of innovation, the project of Tempio Pausania lead us to work on the start-up of the restorative and counselling service open to all citizens.

\section{Findings and further perspectives}

Starting from October 2018, our project has expanded its boundaries and horizons. In fact, the last result of the project also involved eight neighbouring municipalities. In some of the social service's actions, the detainees of Nuchis prison house are directly involved in the promotion of the community's wellbeing.

The actions of the restorative counselling service were activated following a participatory decision-making process with various municipal administrations and services involved.

As an unexpected result in term of de-radicalisation, from the interviews made with the prisoners about the project, we can underline that detainees involved in Tempio Pausania distanced themselves from mafia culture and are avoiding all the situations in the prison where the others speak about mafia crime. Furthermore, they declare to have a more deep understanding of the harms done to their victims through the restorative conference and the debate with citizens.

In conclusion we can highlight that the Tempio Pausania model has extended its influence in others restorative city projects like Mentana (near Rome) and Palermo.

The project has its own web page supported by the Municipality where one can find further information.

\section{References}

Aos, S., Miller, M. \& Drake, E. (2006). Evidence-based public policy options to reduce future prison construction, criminal justice costs, and crime rate. Olympia: Washington State Institute for Public Policy, Document No. 06-10-1201. 
Catalano, R.F., Berglund, M.L., Ryan, J.M., Lonczak, H.S. \& Hawkins, J.D. (2004). Positive youth development in the United States: research findings on evaluations of positive youth development programs. Annals of the American Academy of Political and Social Science, 59, 198-124. doi:10.1177\%2F0002716203260102.

Cellini, G. (2009). Alternative al carcere: la Intensive Probation e un esempio di trattamento intensivo efficace. Rassegna Italiana di Criminologia, 1, 37-56.

De Leo, G. (1985). Responsabilità: definizioni e applicazioni nel campo della giustizia minorile. In G.L. Ponti (ed.), Giovani, responsabilità e giustizia (pp. 33-65). Milano: Giuffrè.

De Leo, G. (1996). Psicologia della responsabilità. Bari: Laterza.

Masten, A.S. \& Powell, J.L. (2003). A resilience framework for research, policy, and practice. In S.S. Luthar (ed.), Resilience and vulnerability: adaptation in the context of childhood adversities (pp. 1-25). New York: Cambridge University Press.

McIvor, G. (1991). Social work intervention in community service. British Journal of Social Work, 21, 591-610. doi:10.1093/oxfordjournals.bjsw.a055809.

McMillan, D.W. \& Chavis, D.M. (1986). Sense of community: a definition and theory. Journal of Community Psychology, 14, 6-23. doi: 10.1002/1520-6629(198601)14:1\%3C6::aid-jcop2290140103\%3E3.0.co;2-i.

Miers, D. \& Aertsen, I. (eds.) (2012). Regulating restorative justice. A comparative study of legislative provision in European countries. Frankfurt am Main: Verlag für Polizeiwissenschaft.

Nota, L., Ginevra, M.C. \& Santilli, S. (2015). Life design and prevention. In L. Nota, J. Rossier, L. Nota, \& J. Rossier (eds.), Handbook of life design: from practice to theory and from theory to practice (pp. 183-199). Boston: Hogrefe Publishing.

Patrizi, P. \& Lepri, G.L. (2011). Le prospettive della giustizia riparativa. In P. Patrizi (ed.), Psicologia della devianza e della criminalità. Teorie e modelli di intervento (pp. 83-96). Roma: Carocci.

Petersilia, J. \& Turner, S. (1993). Evaluating intensive supervision probation/parole: results of a nationwide experiment. Washington: Department of Justice, National Institute of Justice.

Seligman, M. (2005). Imparare l'ottimismo - Come cambiare la vita cambiando il pensiero. Firenze: Giunti.

Snyder, C.R. (2000). Handbook of hope: theory, measures \& applications. San Diego: Academic Press.

Snyder, C.R., Lopez, S.J. \& Pedrotti, J.T. (2011). Positive psychology the scientific and practical explorations of human strengths. Thousand Oaks: Sage.

Spreitzer, G.M. \& Sonenshein, S. (2003). Positive deviance and extraordinary organizing. In K. Cameron, J. Dutton \& R. Quinn (eds.), Positive organizational scholarship (pp. 207-224). San Francisco: Berrett-Koehler.

Wright, M. (2002). In che modo la giustizia riparativa è riparativa? Rassegna Penitenziaria e Criminologica, 3, 153-178.

Wright, M. (2010). Towards a restorative society: a problem-solving response to harm. London: MakeJustice Work.

Zehr, H. (1990). Changing lenses: a new focus on crime and justice. Scottdale: Herald Press. 